\title{
Is food insecurity a problem among the elderly in Sharpeville, South Africa?
}

\author{
Wilna Oldewage-Theron ${ }^{1} \cdot$ Abdulkadir A. Egal $^{2}$ (D) \\ Received: 18 January 2019 / Accepted: 22 November 2020 / Published online: 5 January 2021 \\ (C) International Society for Plant Pathology and Springer Nature B.V. 2021
}

\begin{abstract}
The objective of this study was to determine the prevalence of food and nutrition insecurity and assess the sociodemographic factors associated with food and nutrition insecurity among 146 free-living elderly persons attending a care centre in Sharpeville, South Africa. Measurement instruments included socio-demographic-, 24-hour-recall and dietary diversity questionnaires and the validated household food insecurity access scale/score (HFIAS). Data were analysed with IBM SPSS Software, version 25.0. The prevalence of food insecurity from HFIAS was $60 \%(n=87)$, with a variety of balanced responses being employed. Significant relationships were observed between HFIAS and age $(\mathrm{r}=0.301 ; p=0.000)$ and with household income $(\mathrm{r}=-0.258 ; p=0.007)$. An association was observed between HFIAS and marital status $(p=0.005)$. Regression analysis showed that age and being single were predictors of food and nutrition insecurity. This study indicated a problem of household food insecurity with poor dietary intakes among these elderly people, mostly due to poverty and being single. More research on associations between food security and socioeconomic variables is needed to plan and implement appropriate strategies to address food and nutrition insecurity in South Africa.
\end{abstract}

Keywords Coping $\cdot$ Dietary intakes $\cdot$ Elderly $\cdot$ Food insecurity $\cdot$ HFIAS $\cdot$ Socioeconomics $\cdot$ South Africa

\section{Introduction}

This study is a follow-up to previous studies (OldewageTheron et al. 2006, 2008) of the same cohort of free-living elderly persons who are regular voluntary attendees of an urban day-care centre in Sharpeville, South Africa. Attendees receive breakfast and lunch as well as cultural, religious and physical exercise activities 3 days a week. The care centre is managed by a religious organisation and was opened in 2004 with the purpose of caring for elderly people from resourcepoor households who are responsible for their Human Immuno Virus (HIV) and Autoimmune deficiency syndrome (AIDS)-affected grandchildren. This is the only elderly care

Abdulkadir A. Egal

abdul@vut.ac.za

1 Department of Nutritional Sciences, Texas Tech University, Lubbock, TX, USA

2 Centre of Sustainable Livelihoods, Vaal University of Technology, Vanderbijlpark, South Africa centre in Sharpeville, one of the oldest townships in the Vaal Region of Gauteng Province, South Africa.

A previous study in 2006 (Oldewage-Theron et al. 2006) indicated a high prevalence of poverty, inadequate dietary intakes and malnutrition amongst the same cohort of elderly people. In addition, the average household had five members and the majority (83\%) of the households spent less than ZAR 200 (US\$30) on food per week. Although food security was not measured in this elderly community before, previous studies have shown that $48 \%$ of the elderly often and $7 \%$ always experienced a shortage of money for food. The majority bought most of their food monthly ( $82 \%)$ and from supermarkets $(68 \%)$, informal shops and markets in the community $(13 \%)$ and street vendors (2\%). The rest bought their food from a combination of these food vendors (OldewageTheron et al. 2008). A recent national study has shown that $30 \%$ of the elderly population in South Africa are food insecure (Grobler and Dunga 2019). This was the only recent study that could be found measuring food insecurity in the elderly population. Very little literature exists in South Africa on the relationship between two measures of food security, namely the Household Food Insecurity Access Scale 
(HFIAS) and the Household Dietary Diversity Score (HDDS) (Coates et al. 2007; Izraelov and Silber 2019). Also, very little is known about the relationships among socio-economic and demographic factors and food and nutrition insecurity for older people in South Africa. Thus, there is a need for more research on the dimensions of food insecurity in South Africa.

Food insecurity often results in hunger and malnutrition (Walsh and van Rooyen 2015) and may have detrimental health outcomes such as obesity and its chronic disease comorbidities. Food insecurity is caused by many factors, one of which is an ageing population (Walsh and van Rooyen 2015). South Africa has experienced an increase in the aged ( $\geq 60$ years) ("Old age pension $\mid \mathrm{S}$ A Government" n.d.) and it is projected that the number of older people in the country will be seven million by 2030, an increase of almost $71 \%$ between 2011 and 2030 (Pillay and Maharaj 2013). Despite the widely observed increase in population ageing, few lowand-middle income countries have given attention to the nutritional challenges of the elderly (Aboderin and Beard 2015) and government policies and strategies often overlook the risk of food and nutrition insecurity synergies on nutritional and health status in this population group (Altman et al. 2009; UNDESA 2019). In addition, in many African countries, older populations are less socio-economically advanced and live in poverty (Audain et al. 2017). Poverty is an underlying cause of food insecurity (Wight et al. 2014). Thus, the elderly is a vulnerable group due to their high poverty risk (Gorman 2017; Keller et al. 2007), and high burden of chronic noncommunicable diseases (NCDs) (UNDESA 2019) associated with inadequate access to food and nutrition (Baiphethi and Jacobs 2009).

The United Nations Food and Agriculture Organization (FAO) (1996) definition that 'food security exists when all people at all times have physical, social and economic access to food of sufficient, safe and nutritious food that meets their dietary needs and food preferences for an active and healthy life' is widely accepted. This definition identified four dimensions of food security: availability, access, stability and utilisation (Committee on World Food Security 2012). Food insecurity exists when these conditions are impacted, for example limited food production, processing, imports and food aid affecting food availability at a national level or poor household access due to limited physical or economic resources. Utilisation refers to how food is allocated to the individuals in the household, nutritional quality and quantity, and conditions that may compromise absorption and metabolism of the nutrients in food (FAO 1996; Jones et al. 2013).

When measuring food security, very simple or highly comprehensive measures can be used to assess one or all of the four dimensions. In addition, food security measurements can be focused at the national, household or individual levels. It is, therefore, important to specify what and how food security is measured. From a review of national surveys in South Africa we found that measurement of access to food has received particular attention because food may be available in the markets, but households may not have the resources to access the food. The Community Childhood Hunger Identification Project (CCHIP) index was validated and most frequently used in studies (Labadarios et al. 2011). Household access to food can be measured using several different metrics, including household consumption and expenditure surveys, household dietary diversity score (HDDS), food consumption score, household food insecurity access score (HFIAS), and the household hunger scale (FANTA III and USAID 2007; Izraelov and Silber 2019; Jones et al. 2013). In our study we used the HFIAS and HDDS. HFIAS is a validated method for measuring household food access and was developed by the Food and Nutrition Technical Assistance, United States Agency for International Development (USAID). A strength of HFIAS is that it is widely used to measure food access impacts of programes, although a limitation is that the food quality questions do not measure nutritional quality or measure the household's perception of changes to their diet quality (Maarof 2018). Other measures of diet quality should thus be included (FANTA III and USAID 2007). HFIAS relies on a subjective report of food insecurity experiences which is another limitation because a change in household experiences or values may result in a change in perceptions of food insecurity experiences (Jones et al. 2013). HDDS is a simple count of foods and food groups. It is a qualitative measure of food consumption in terms of a household's access to a variety of foods. It can be used as a proxy indicator for micronutrient intake, but not for assessing dietary diversity of individuals (Coates et al. 2007). A strength of the HDDS questionnaire is that it is a low-cost assessment tool that is quick and easy to administer, and easy to score as the HDDS is a simple count of food groups that a household has consumed over the preceding 24 hours (Drewnowski 2005; Guthrie and Scheer 1981).

This study was the first to determine the prevalence of food and nutrition insecurity in this community and addressed the paucity of information by assessing sociodemographic factors associated with food and nutrition insecurity among these older people. A better understanding of these factors is necessary to help design and target interventions to ensure a good quality of life and health for the aged (Kautz et al. 2010). Accordingly, our main objective with this paper is to report on an investigation into the association between HFIAS and HDDS with socio-economic factors in a group of the elderly in Sharpeville, South Africa. 


\section{Methods}

\subsection{Ethical clearance}

The study protocol was performed in accordance with the South Africa Medical Research Council guidelines and approved by the Vaal University of Technology Senate Research Innovation and Ethics Committee (20140827mns). All the participants completed and signed the informed consent forms for voluntary participation.

\subsection{Study participants}

The respondents considered for this study were the 146 surviving participants from a cohort study that, at the baseline in 2004, included 368 free-living elderly people from a day-care centre in Sharpeville - an urban settlement in Gauteng province of South Africa (Oldewage-Theron et al. 2008). This study was carried out in June 2017 and all the respondents were homogeneous in age ( $\geq 60$ years), race (black), were resident in Sharpeville and were state pensioners.

\subsection{Data collection}

Measurement instruments included a validated sociodemographic and economic questionnaire (OldewageTheron et al. 2008) to measure age, household size, gender distribution, marital status, education, monthly household income, weekly food expenditure, and the frequency and place of food procurement. Household income was measured as a categorical variable as well as through a question to indicate the income from various sources such as old age pension (social security grants), gifts or donations from children or other family members, or any other income. All these were totalled for the monthly household income. The validated five-step multiple pass method (Gibson 2005) was used to complete the 24-h recall questionnaire for a week day and a weekend day to measure actual food and nutrient intakes. The 24-h dietary recall method is one of the most commonly used dietary assessment tools for sample sizes of more than 50 as it is an easy, quick and inexpensive retrospective method suitable for use among persons with low literacy and the elderly because it does not rely on the long term memory of respondents (Gibson 2005; Thompson and Subar 2017). An adapted validated Dietary Diversity Questionnaire (DDQ) (Matla 2008) was used as a reference measure for both the 24-h recall and the Household Food Insecurity Access Scale (HFIAS) questionnaire (Coates et al. 2007). Although a more recent measurement for HDDS was published in 2016 (FAO 2016), the nine-group HDDS was used to compare results from studies previously undertaken in the same cohort of elderly people. All these questionnaires have been used with the same cohort of elderly in previous studies and used again to compare results from the previous studies. Food insecurity was not measured in this community in the previous study and the HFIAS was used for the first time in 2017 to measure food access and prevalence of food insecurity. HFIAS was selected as it is used for monitoring food insecurity of programmes (Coates et al. 2007; Jones et al. 2013). This elderly community forms part of a cohort study with various interventions implemented by the researchers over the years since 2006. All the questionnaires were administered by trained fieldworkers in a one-on-one interview. The 24-h recall was completed for a week day and a weekend day using standardised methods (Gibson 2005). The data used in this paper were collected in June 2017.

\subsection{Data analyses}

Data were analysed using IBM SPSS, version 25 . The sociodemographic data were analysed for descriptive statistics (means, standard deviations [SDs], frequencies) for the total group of respondents. The 24 -h recall data was analysed using the FoodFinder3 dietary analysis software program (MRC 2002). FoodFinder3 is a data capture program that includes the South African Food Composition Database System (SAFOODS) and Food Quantities Manual (FQM) that are managed by the Medical Research Council in South Africa (Wolmarans et al. 2009). An average intake of the week day and weekend day was calculated for all macro- and micronutrients. The dietary intake average for each nutrient was transferred to the IBM SPSS Software program and medians were calculated for the nutrient intakes per person per day (total of two 24-h recall/2) and compared with the Dietary Reference Intakes (DRI), specifically the Estimated Average Requirement (EAR) for the age group $>70$ years (IoM 1997, 2000, 2001, 2002). Medians with interquartile ranges (IQRs) were used for the dietary intake variables as these were not normally distributed. The DDQ was statistically analysed for descriptive statistics (frequencies, medians and quartiles) according to the different cut-off points (Matla 2008) for food variety (FVS) (a simple count of food items consumed) and HDDS (a simple count of all the food groups consumed) (Drewnowski 2005; Guthrie and Scheer 1981; Hatløy et al. 1998). Individual food insecurity levels were analysed from the data collected with the HFIAS questionnaire, calculated according to the procedures described by Coates et al. (2007) and grouped according to the four Household Food Insecurity Access Prevalence (HFIAP) status ordinal categories; $1=$ Food Secure, 2 = Mildly Food Insecure Access, $3=$ Moderately Food Insecure Access, $4=$ Severely Food Insecure Access (Coates et al. 2007). The sample was further categorised as food secure (HFIAP category 1 ) and food insecure (HFIAP mild Category $2+$ HFIAP moderate Category $3+$ HFIAP severe Category 4 food insecurity) using the 
Coates et al. (2007) classification. Frequencies were calculated for each of the HFIAP categories as well as for the behavioural responses to food insecurity as part of the nine HFIAS questions. The HFIAS score was calculated by adding the sum of all follow-up questions (1a to 9a) testing the severity of food insecurity; thus, the resulting score was from zero to 27 (Coates et al. 2007).

Data were compared between the food secure and food insecure groups. The severely food insecure group had only two people and was thus not considered for the analyses. Analysis of Variance (ANOVA) with the correction of Bartlett's test for equal variances at a significance level of $p \leq 0.05$ was used to determine significant differences for the numerical data between the groups. Multivariate analysis (MANOVA) was conducted to explore the effects of other dependent variables that ANOVA had not measured directly. Non-parametric hypothesis test summaries were performed for categorical data to determine significant differences between the groups. Pearson correlations were used to determine significant relationships between numerical variables. Only significant relationships are reported in the results. ChiSquare tests were used to determine associations between categorical variables. Regression analysis for predictors was also employed to identify socio-economic and dietary intake factors that could explain the existing food insecurity status among these elderly people.

\section{Results}

\subsection{Respondent characteristics}

The mean \pm SD age of the participants was $78 \pm 7$ years (Table 1). The sample was exclusively black and comprised of $71 \%$ women and $29 \%$ men. Most were Sotho-speaking $(83 \%)$. Of the respondents, $31 \%$ were married with the rest being either divorced $(32 \%)$, single $(11 \%)$ or widowed $(2 \%)$, while $24 \%$ declined to give their status. Only $9 \%$ lived alone whilst the rest shared their houses with family (mean $\pm \mathrm{SD}$ household size of $4.5 \pm 2.4$ persons).

The respondents had relatively poor education; $30 \%$ had no formal education and $34 \%$ had only primary school education. All the subjects participating in the study received a state pension. In $60 \%$ of the households, this was the only income. Most of the respondents had a monthly household income of $\leq$ ZAR2000 (\$154) and the mean monthly household income was ZAR2068.38 (\$159). The majority of the respondents $(83 \%)$ spent less than ZAR300 (\$23) per week on food provisions and these were mainly bought from a supermarket $(63 \%)$ and informal food vendors in the residential area (37\%). Food shopping occurred monthly (79\%) in most households, followed by weekly (13\%) and daily (8\%) shopping.

\subsection{Prevalence of food insecurity}

We used HFIAS and HFIAP (Coates et al. 2007) to determine food insecurity among the elderly group participating in this study. The majority $(67 \%)$ of the elderly respondents were food secure, with $10 \%, 19 \%$ and $4 \%$ presenting with mild, moderate and severe food insecurity (see Table 2 and Coates et al. (2007)). The majority of the elderly $(77 \%)$ worried that they did not have enough food in the house to feed the family. The behavioural responses to food insecurity showed that $49 \%$ of the elderly respondents reported that they were not able to eat their preferred foods and $41 \%$ consumed fewer kinds of foods, and thus compromised on their dietary diversity. In addition, $47 \%$ of the elderly consumed foods they did not really want to eat due to limited resources. They also reported cutting portion sizes by consuming smaller meals (39\%), consuming fewer meals (39\%), and going without food at times due to lack of food available in the household $(32 \%)$.

No significant differences were observed between age and education level among the HFIAP groups. However, a trend was observed that the food secure group had a higher percentage of respondents with secondary school education $(11 \%)$ than the food insecure groups (1\% and $54 \%$ respectively). A significant difference $(p=0.048)$ was observed in the marital status of the groups with $29 \%$ of the respondents being married in the food secure group, compared to only $6 \%$ in the mildly food insecure group and $10 \%$ in the combined and severe food insecure groups. In addition, the food secure group had a significantly ( $p=$ $0.011)$ higher mean \pm SD monthly household income (ZAR3101.63 \pm 3017.93 ) than the food insecure groups (Tables 1 and 4). Furthermore, income was progressively lower as food security status deteriorated. In the food procurement frequency of table, the majority $(64 \%, n=32)$ of the food insecure households did monthly food shopping followed by $20 \%$ weekly and $16 \%$ monthly. Interestingly, no significant $(p=0.496)$ differences were observed among the HFIAP groups for weekly food expenditure. Frequency of food procurement also showed no significant ( $p=0.270)$ differences among HFIAP groups, with the majority of food secure and mildly food insecure respondents doing daily ( $81 \%$ and $64 \%$ respectively) food shopping, compared to $100 \%$ of the moderately food insecure respondents doing monthly food shopping. No significant ( $p=$ 0.631 ) differences were observed for HDDS among the HFIAP groups (Table 1). The MANOVA analysis in Table 4 indicated a significant difference in income among the HFIAP categories when controlled for gender, education, marital status, number of people in the household, income and money spent on food (tests between subject effects $p=0.049$ ). This was confirmed by the separate 
Table 1 Socio-economic parameters compared across the food security groups $(n=146)$

\begin{tabular}{|c|c|c|c|c|}
\hline Variables & $\begin{array}{l}\text { Food secure group } \\
(n=59,40 \%) \\
\text { Prevalence }(\%) / \\
\text { Mean } \pm \text { SD }\end{array}$ & $\begin{array}{l}\text { Mild food insecure } \\
\text { group }(n=29,20 \%) \\
\text { Prevalence }(\%) / \\
\text { Mean } \pm \text { SD }\end{array}$ & $\begin{array}{l}\text { Moderate \& severe food } \\
\text { insecure group }(n=58,40 \%) \\
\text { Prevalence }(\%) / \text { Mean } \pm \text { SD }\end{array}$ & $\begin{array}{l}\text { Significance of } \\
\text { differences } \\
\text { among groups } p\end{array}$ \\
\hline Age & $73.5 \pm 6.4$ & $78.7 \pm 7.9 .342$ & $80.6 \pm 7.2$ & 0.114 \\
\hline Number of household members & $4.5 \pm 2.4$ & $4.3 \pm 1.9$ & $4.6 \pm 2.8$ & 0.761 \\
\hline \multicolumn{5}{|l|}{ Gender: } \\
\hline Women & 41 & 15 & 48 & \\
\hline Men & 18 & 14 & 10 & \\
\hline Education: & & & & 0.219 \\
\hline None & 14 & 8 & 22 & \\
\hline Primary school & 23 & 10 & 16 & \\
\hline Secondary school & 11 & 1 & 5 & \\
\hline College or tertiary education & 2 & 1 & 4 & \\
\hline Marital status: & & & & 0.048 \\
\hline Single & 9 & 5 & 2 & \\
\hline Married & 29 & 6 & 10 & \\
\hline Divorced & 12 & 8 & 27 & \\
\hline Widowed & 0 & 2 & 0 & \\
\hline Monthly household income: & & & & 0.011 \\
\hline$\leq$ ZAR1000 (US\$77) & 21 & 17 & 40 & \\
\hline$>$ ZAR1000 $\leq$ ZAR2000 (>77US\$ $\leq 154$ US\$) & 11 & 8 & 12 & \\
\hline$>$ ZAR $2000 \leq$ ZAR3000 $(>$ US\$154 $\leq$ US\$231) & 13 & 1 & 6 & \\
\hline$>$ ZAR $3000 \leq$ ZAR4000 (>US\$231 $\leq$ US $\$ 308)$ & 5 & 0 & 0 & \\
\hline 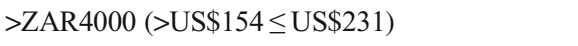 & 9 & 3 & 0 & \\
\hline Mean household income & $3101.63 \pm 3017.93$ & $1782.73 \pm 184.40$ & $1320.77 \pm 436.41$ & \\
\hline Only contributor to household income & 8 & 7 & 22 & \\
\hline Two contributors to household income & 5 & 2 & 12 & \\
\hline More than two contributors to household income & 0 & 2 & 4 & \\
\hline Money spent on food per week: & & & & 0.452 \\
\hline$<$ ZAR300 (<US\$23) & 5 & 8 & 21 & \\
\hline 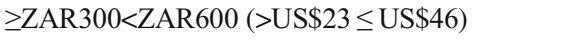 & 9 & 6 & 16 & \\
\hline Frequency of food procurement: & & & & 0.270 \\
\hline Once a month & 8 & 10 & 32 & \\
\hline Once a week & 4 & 0 & 4 & \\
\hline Every day & 2 & 1 & 0 & \\
\hline Place of food procurement: & & & & 0.269 \\
\hline Supermarket & 8 & 6 & 26 & \\
\hline Street vendor & 2 & 3 & 5 & \\
\hline Kiosk in residential area & 4 & 3 & 7 & \\
\hline HFIAS & $0.6 \pm 0.4$ & $2.4 \pm 1.0$ & $6.76 \pm 1.9$ & 0.017 \\
\hline \multicolumn{5}{|l|}{ Dietary diversity } \\
\hline FVS & $23.76 \pm 7.5$ & $23.76 \pm 7.5$ & $30.12 \pm 14.3$ & 0.128 \\
\hline HDDS & $7.42 \pm 1.2$ & $7.9 \pm .87$ & $7.0 \pm 0.0$ & 0.391 \\
\hline
\end{tabular}

ANOVA that was conducted for each of the six dependent variables with an alpha level of 0.025 .

\subsection{Dietary intakes}

The dietary intake results in Table 3 show that both the food secure and insecure groups had low median nutrient intakes compared to the Estimated Average Requirement (EAR) for 
Table 2 The four categories of food insecurity of the study respondents (access)

Frequency

$\begin{array}{lll}\text { Rarely } 1 & \text { Sometimes } 2 & \text { Often } 3\end{array}$

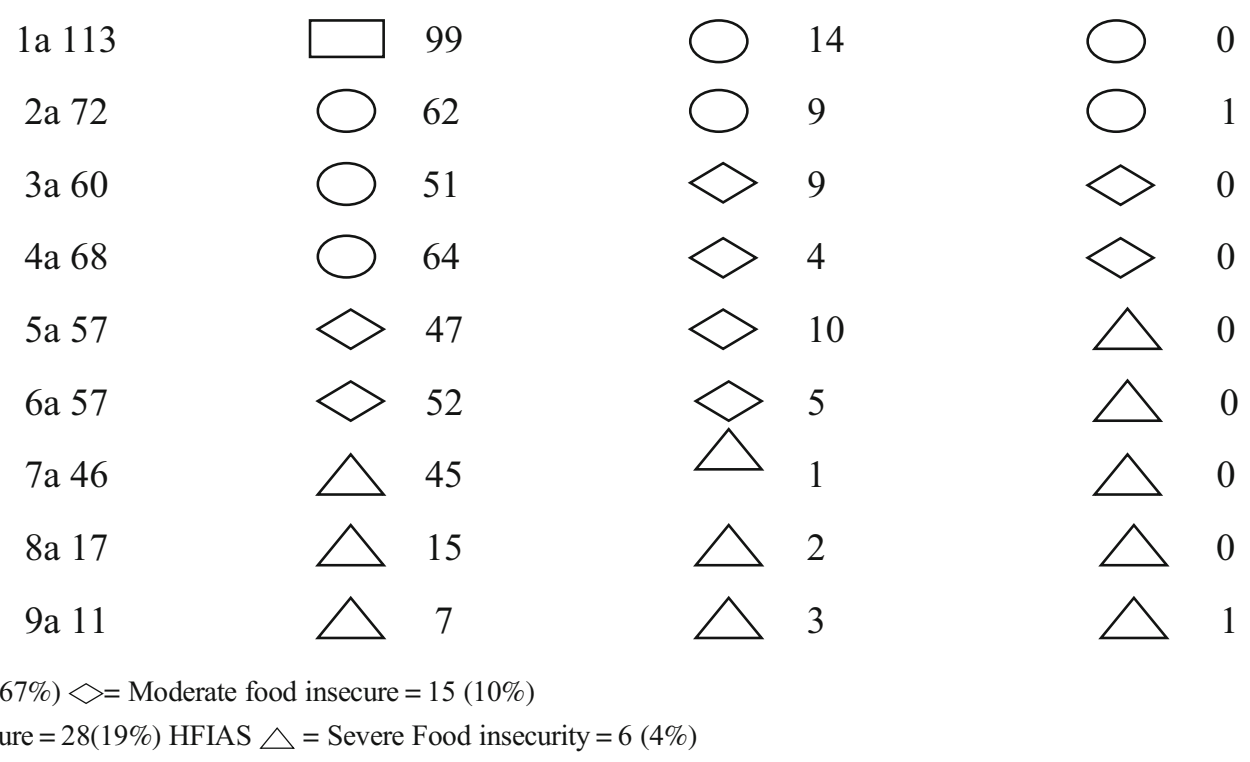

total energy and for most nutrient intakes. Although median carbohydrate and iron intakes reflected adequacy when compared to EAR, a large percentage of the respondents had low intakes for these nutrients $(29 \%, 17 \%$ and $25 \%$ for carbohydrate and $51 \%, 68 \%$ and $44 \%$ for dietary iron in the food secure, mildly and moderately food insecure groups respectively). Although the food secure group showed adequate intakes for dietary protein, $50 \%$ of the respondents did not meet the EAR. Similarly, large percentages $(>67 \%)$ of the respondents in all HFIAP groups did not meet the EAR for dietary fibre, dietary calcium, magnesium and vitamin $\mathrm{C}$ intakes. In addition, no significant differences were observed in nutrient intakes among the HFIAP groups, except for dietary fibre $(p=$ $0.011)$ and magnesium $(p=0.015)$ where higher intakes were observed among the food secure group.

The median HDDS for the total group was 7.5. This reflected high food variety (6-9 food groups) (Matla 2008) for the total group. No significant differences between the food security groups were observed for HDDS and FVS and this was confirmed by a multivariate analysis. Interestingly, the FVS for all HFIAP groups showed low food variety $(<30$ individual foods consumed). This result showed that although the HDDS was high, poor variety within the nine food groups was evident. Concomitantly, no significant correlations were observed between HDDS, FVS and FS (Table 4).

A significant positive relationship was observed between HFIAS (proxy for food security/insecurity) and age $(r=$ $0.301 ; p=0.000)$ at the $99 \%$ confidence level $(p=0.001)$, as well as a significant inverse relationship with income $(r=$ $-0.258 ; p=0.007)$. In addition, a significant $(p=0.005)$ association was found between HFIAS and marital status. This was consistent with the earlier study by Grobler and Dunga (2019) in South Africa. No significant relationships or associations were observed between HFIAS and any other variables.

The regression analysis carried out on the sociodemographic predictors of food security (HFIAS) showed that age and being single were predictors of FS $(r=43 \% p=0.000$, $\mathrm{SEE}=3.22174)$.

\section{Discussion}

Globally, the number of elderly people ( $\geq 60$ years) is rising sharply (WHO 2019). In South Africa the elderly now represent $8 \%$ of the population (Statistics South Africa 2018). Although elderly persons are considered vulnerable to food insecurity (Bain et al. 2013), as we indicated in the Introduction, very little is known about the food security status of elderly people in South Africa (Denny et al. 2018). The objective of this research was thus to contribute to an understanding of the extent of food insecurity and the socioeconomic predictors of food insecurity in resource-poor elderly households in Sharpeville.

The results of this study confirmed that, although South Africa is food secure at the national level, food insecurity is still widely experienced in households (Statistics South Africa 


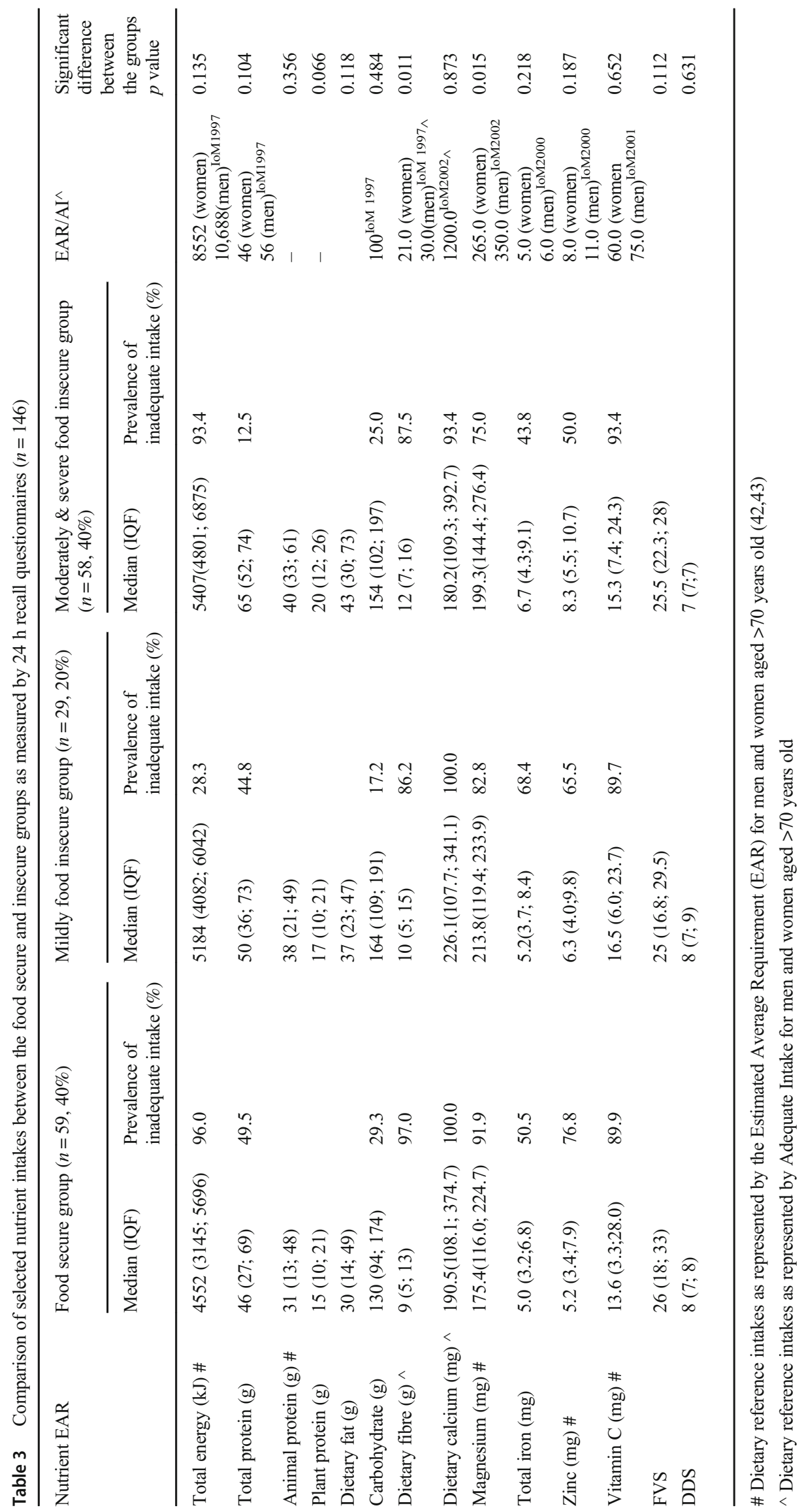


Table 4 Multivariate Analysis of mean difference between food security categories with respect to Socio-demographic variables

\begin{tabular}{|c|c|c|c|c|c|c|}
\hline & & & $\mathrm{N}$ & Mean & SD & \\
\hline \multirow[t]{4}{*}{ FScat } & 1 & Food Sec. & 59 & 0.40 & 0.42 & \\
\hline & 2 & Mild & 29 & 0.40 & 0.80 & \\
\hline & 3 & Moderate & 12 & 0.25 & 0.83 & \\
\hline & 4 & Severe & 46 & 1.26 & 1.87 & \\
\hline \multicolumn{7}{|c|}{ Multivariate Tests } \\
\hline Effect & Value & & $\mathrm{F}$ & Hypothesis df & Error df & Sig. \\
\hline \multirow[t]{4}{*}{ FScat } & Pillai's Trace & & .214 & .678 & 18.000 & 159.000 \\
\hline & Wilks' Lambda & & .796 & 677 & 18.000 & 144.735 \\
\hline & Hotelling's Trace & & .246 & .678 & 18.000 & 149.000 \\
\hline & Roy's Largest Root & & .188 & 1.662 & 6.000 & 53.000 \\
\hline \multicolumn{7}{|c|}{ Tests of Between-Subjects Effects } \\
\hline Source & Dependent Variable of & & df & Mean Square & $\mathrm{F}$ & Sig. \\
\hline \multirow[t]{6}{*}{ FScat } & Gender & .139 & 3 & .046 & .340 & .797 \\
\hline & Education & 1.065 & 3 & .302 & .401 & .753 \\
\hline & Marital Status & .276 & 3 & .488 & 1.400 & .252 \\
\hline & Nr People in $\mathrm{HH}$ & 5.177 & 3 & 3.803 & .583 & .629 \\
\hline & Income & $1,203,004.808$ & 3 & $\begin{array}{l}417,378.917 \\
401,001.603\end{array}$ & 2.791 & .049 \\
\hline & Money Spent on food & 22.980 & 3 & 7.660 & 1.277 & .291 \\
\hline \multirow[t]{6}{*}{ Error } & Gender & 7.511 & 56 & .134 & & \\
\hline & Education & 41.919 & 56 & .749 & & \\
\hline & Marital Status & 20.707 & 56 & .370 & & \\
\hline & $\mathrm{Nr}$ People in HH & 371.823 & 56 & 6.640 & & \\
\hline & Income & $8,046,995.192$ & 56 & $143,696.334$ & & \\
\hline & Money Spent on food & 351.469 & 56 & 6.276 & & \\
\hline
\end{tabular}

2019). In our study of a very marginalized group, $60 \%$ of the elderly were found to be food insecure. This is comparable to another recent South African study that found a prevalence of $30.2 \%$ food insecurity among the elderly (Grobler and Dunga 2019). Poverty is unquestionably the driving force for food insecurity due to limited resources to procure food (Bain et al. 2013). The food insecure elderly group in this study had a lower monthly household income and as their income declined, their food security status deteriorated. Overall, South Africa is a middle-income country, but the food secure group in this study lived on just US\$1.74 per day compared to US $\$ 1.52$ and US\$0.74 for the mildly and moderately food insecure elderly groups. Based on the international poverty line of US1.90 per person per day (The World Bank n.d.), all members of this elderly community can be considered poor despite almost two thirds being food secure. Government initiatives targeting food insecurity involve social grants, including old age pension funds for elderly aged 60 years and older with no other income (South African Government n.d.). This was evidenced by the majority of the households (60\%) in our study that depended on the old age pension fund for purchasing food and other items. For $55 \%$ of the food secure households, the old age pension provided their only income, compared to $62 \%$ in the mildly- and $80 \%$ in the moderately food insecure households. While social grants can play a significant role in reducing poverty and food insecurity in South African households, receiving social grants is not enough to alleviate poverty (Hendriks 2014) and achieve food security (Grobler and Dunga 2019) as we demonstrated in our study.

Poverty has also been linked to levels of education (Bain et al. 2013). In this study the majority of the elderly had less than or the equivalent of only a primary school education. We found no association between food insecurity and levels of education, although the cycle of unawareness, disease and poverty is well known elsewhere (Park et al. 2019). Furthermore, low education levels are key to poor nutrition practices (Bain et al. 2013). Food insecure households are often at risk of food shortages and this leads to the adoption of behavioural responses to food insecurity that could adversely impact the food security of households in the short and long term (Maxwell et al. 1999; Ngidi and Hendriks 2014). Behavioural responses to food insecurity in our study included a large percentage of the elderly that were not able to eat their preferred food choices and had to eat foods they did not want and with a limited variety. Although most food groups were consumed, monotony in the diet, as evidenced by the dietary 
intakes, is associated with poverty and poor nutrition (Shariff and Khor 2008). These findings were consistent with those from other South African studies by Hendriks (2014) and by Shisana et al. (2015). We found the elderly consumed fewer and smaller meals to cope with their food insecurity situation. In almost a third of the households, there was no food to eat at some time during the previous month. These behavioural responses to food insecurity are consistent with the low intakes of nutrients observed in this elderly sample. Our dietary intake results showed that both the food secure and the insecure groups had low median nutrient intakes compared to the EAR. Interestingly, no significant differences in most nutrient intakes were observed between the food insecure groups when compared with the food secure elderly group. However, the very high prevalence $(\geq 75 \%)$ of inadequate intakes of dietary calcium, magnesium and vitamin $\mathrm{C}$, as well as high prevalence ( $\geq 50 \%)$ of inadequate intakes of dietary total iron and zinc, point to consistently observed poor dietary intakes in this community found since 2008 (Oldewage-Theron and Kruger 2008). Poor dietary intakes, specifically of zinc and iron, may result in poor immunity, which can lead to an increased risk of chronic diseases (Oldewage-Theron and Kruger 2008), which is exacerbated by the high prevalence of overweight and obesity among the respondents. Obesity is associated with 38 comorbidities (The Obesity Society n.d.). Most of the human disease states can also adversely affect dietary intakes. A vicious circle of poverty, leading to food insecurity, leading to poor dietary intakes, leading to malnutrition, leading to higher physical and economic burdens, leading to more poverty may thus be the result. Preventing poor health among the elderly will reduce the burden that population aging has on society and health budgets in many countries (Park et al. 2019). Thus, the effects of food insecurity among the elderly in this community and elsewhere are many and need to be addressed. If the food insecurity exists with already fragile elderly people, they will be more susceptible to diseases and so morbidity and mortality will be higher because of the body's need for extra nourishment during disease states (Shetty 2009). This is the case for the current Covid-19 pandemic (Hewitt et al. 2020).

A limitation of our study is that the $24-\mathrm{h}$ recall questionnaire relied on memory and underreporting may have led to an overestimation of the prevalence of inadequate nutrient intakes compared to the EAR. In addition, allocating inappropriate wrong food codes or analysis in the FoodFinder program may result in error. To minimize this, all the food codes were allocated by a Registered Dietitian and Nutritionist respectively (Wolmarans et al. 2009). Both had a good knowledge of the composition and preparation methods of foods. Another limitation of this study was that our food insecurity results were self-reported and, although there are several advantages to using behavioral responses when measuring food insecurity (see Maxwell et al. 1999), more research is needed as other behavioral responses to food insecurity that may been specific to this elderly group could have been excluded. The results of this study can thus not be generalized to other elderly communities, but the lessons learnt from this study can help guide similar studies.

It was difficult to compare our results across other similar studies because of the paucity of data for food insecurity of elderly populations in South Africa, as well as the different measurement instruments that were used in other studies. However, our study points clearly to a serious problem of household food insecurity among black elderly people in the country. This is consistent with results from elsewhere, including some well-resourced countries such as the United States of America where the elderly population has been identified as one of seven vulnerable groups at risk of food insecurity (e.g., Lee and Frongillo 2001; National Commission on Hunger 2015).

In conclusion, the main finding of our study was that only two demographic variables, the age of a person and marital status, were identified as predictors of food insecurity in this marginalized community in Sharpeville. More studies in South Africa are needed to explore the various sociodemographic variables leading to food insecurity of elderly populations to plan and implement appropriate strategies to address food insecurity effectively and efficiently amongst this group of particularly vulnerable people.

Acknowledgements We thank the National Research Foundation of South Africa for funding this project. We are grateful to the elderly care centre management and participants in this study. We also wish to acknowledge the fieldworkers for their valuable assistance.

\section{Compliance with ethical standards}

Conflict of interest The authors of this study declared that they have no conflict of interest.

Ethical approval All procedures performed in studies involving human participants were in accordance with the ethical standards of the institutional and/or national research committee and with the 1964 Helsinki declaration and its later amendments or comparable ethical standards.

\section{References}

Aboderin, I. A. G., \& Beard, J. R. (2015). Older people's health in subSaharan Africa. The Lancet, 385(9968), e9-e11.

Altman, M., Hart, T. G., \& Jacobs, P. T. (2009). Household food security status in South Africa. Agrekon, 48(4), 345-361.

Audain, K., Carr, M., Dikmen, D., Zotor, F., \& Ellahi, B. (2017). Exploring the health status of older persons in sub-Saharan Africa. Proceedings of the Nutrition Society, 76(4), 574-579.

Bain, L. E., Awah, P. K., Geraldine, N., Kindong, N. P., Siga, Y., Bernard, N., \& Tanjeko, A. T. (2013). Malnutrition in sub Saharan Africa: Burden, causes and prospects. The Pan African Medical Journal, 15(1), 120.

Baiphethi, M. N., \& Jacobs, P. T. (2009). The contribution of subsistence farming to food security in South Africa. Agrekon, 48(4), 459-482. 
Coates, J., Swindale, A., \& Bilinsky, P. (2007). Household food insecurity access scale (HFIAS) for measurement of food access: Indicator guide: Version 3: (576842013-001). American Psychological Association. https://doi.org/10.1037/e576842013-001.

Committee on World Food Security. (2012). Available at: http://www. fao.org/3/a-mf115e.pdf. Accessed 1 Dec 2020.

Denny, R. C. H., Marquart-Pyatt, S. T., Ligmann-Zielinska, A., Olabisi, L. S., Rivers, L., Du, J., \& Liverpool-Tasie, L. S. O. (2018). Food security in Africa: A cross-scale, empirical investigation using structural equation modeling. Environment Systems and Decisions, $38(1), 6-22$.

Drewnowski, A. (2005). Concept of a nutritious food: Toward a nutrient density score. The American Journal of Clinical Nutrition, 82(4), 721-732.

FANTA III \& USAID. (2007). Household Food Insecurity Access Scale (HFIAS) for Measurement of Food Access: Indicator Guide | Food and Nutrition Technical Assistance III Project (FANTA). https:// www.fantaproject.org/monitoring-and-evaluation/household-foodinsecurity-access-scale-hfias. Accessed 4 July 2020.

FAO 1996. (1996). Rome Declaration and Plan of Action. http://www. fao.org/3/w3613e/w3613e00.htm. Accessed 13 July 2020.

FAO. (2016). Minimum dietary diversity for women- a guide to measurement.

Gibson, R. S. (2005). Principles of nutritional assessment. Oxford: Oxford University Press.

Gorman, M. (2017). Development and the rights of older people. The Ageing and Development Report. https://doi.org/10.4324/ 9781315071541-2.

Grobler, W. C. J., \& Dunga, S. (2019). Analysis of food security status among the elderly in South Africa (no. 9412193). Proceedings of International Academic Conferences. International Institute of Social and Economic Sciences. https://ideas.repec.org/p/sek/iacpro/ 9412193.html. Accessed 25 June 2020.

Guthrie, H., \& Scheer, J. (1981). Validity of a dietary score for assessing nutrient adequacy. Journal of the American Dietetic Association, $78(3), 240-245$.

Hatløy, A., Torheim, L. E., \& Oshaug, A. (1998). Food variety-A good indicator of nutritional adequacy of the diet? A case study from an urban area in Mali, West Africa. European Journal of Clinical Nutrition, 52(12), 891-898.

Hendriks, S. (2014). Food security in South Africa: Status quo and policy imperatives. Agrekon, 53(2), 1-24.

Hewitt, J., Carter, B., Vilches-Moraga, A., Quinn, T. J., Braude, P., Verduri, A., Pearce, L., Stechman, M., Short, R., Price, A., Collins, J. T., Bruce, E., Einarsson, A., Rickard, F., Mitchell, E., Holloway, M., Hesford, J., Barlow-Pay, F., Clini, E., Myint, P. K., Moug, S. J., McCarthy, K., Davey, C., Jones, S., Lunstone, K., Cavenagh, A., Silver, C., Telford, T., Simmons, R., Mutasem, T. E. J., Singh, S., Paxton, D., Harris, W., Galbraith, N., Bhatti, E., Edwards, J., Duffy, S., Bisset, C., Alexander, R., Garcia, M., Sangani, S., Kneen, T., Lee, T., McGovern, A., \& Guaraldi, G. (2020). The effect of frailty on survival in patients with COVID19 (COPE): A multicentre, European, observational cohort study. The Lancet Public Health, 5(8), e444-e451.

IoM, I. of M. (1997). Dietary reference intakes for calcium phosphorus, magnesium, vitamin $D$, and fluoride. Washington, DC: National Academies Press.

IoM, I. of M. (2000). Dietary reference intakes for vitamin C, vitamin E, Selenium and Carotenoids: A Report of the Panel on Dietary Antioxidants and Related Compounds, Subcommittees on Upper Reference Levels of Nutrients and of Interpretation and Use of Dietary Reference Intakes and the Standing Committee on the Scientific Evaluation of Dietary Reference Intakes, Food and Nutrition Board, Institute of Medicine. Washington, DC: National Academies Press.
IoM, I. of M. (2001). Dietary reference intakes for vitamin a, vitamin $K$, arsenic, boron, chromium, copper, iodine, iron, manganese, molybdenum, nickel, silicon, vanadium and zinc. Washington, DC: National Academies Press.

IoM, I. of M. (2002). Dietary reference intakes for energy, carbohydrate, fiber, fat, fatty acids, cholesterol, and protein and amino acids. Washington, DC: National Academies Press.

Izraelov, M., \& Silber, J. (2019). An assessment of the global food security index. Food Security, 11(5), 1135-1152.

Jones, A. D., Ngure, F. M., Pelto, G., \& Young, S. L. (2013). What are we assessing when we measure food security? A compendium and review of current metrics. Advances in Nutrition, 4(5), 481-505.

Kautz, T., Bendavid, E., Bhattacharya, J., \& Miller, G. (2010). AIDS and declining support for dependent elderly people in Africa: Retrospective analysis using demographic and health surveys. British Medical Journal, 340, c2841. https://doi.org/10.1136/bmj. c2841.

Keller, H. H., Dwyer, J. J. M., Edwards, V., Senson, C., \& Edward, H. G. (2007). Food security in older adults: Community service provider perceptions of their roles*. Canadian Journal on Aging / La Revue Canadienne du Vieillissement, 26(4), 317-328.

Labadarios, D., Mchiza, Z. J.-R., Steyn, N. P., Gericke, G., Maunder, E. M. W., Davids, Y. D., \& Parker, W. (2011). Food security in South Africa: A review of national surveys. Bulletin of the World Health Organization, 89, 891-899.

Lee, J. S., \& Frongillo, E. A. (2001). Nutritional and health consequences are associated with food insecurity among U.S. elderly persons. The Journal of Nutrition, 131(5), 1503-1509.

Maarof, M. I. (2018). Translation and validation of household food insecurity access scale (HFIAS) and factors associated with food insecurity among households with children aged five to six years old in Tumpat, Kelantan (thesis). Pusat Pengajian Sains Perubatan, Universiti Sains Malaysia. Retrieved from http:/ethesis.usm.my: 8080/jspui/handle/123456789/9604

Matla, M. T. H. (2008). The contribution of food access strategies to dietary diversity of farm worker households on Oranje farm in the Fouriesburg district (RSA) (dissertation). University of Pretoria. Retrieved from https://repository.up.ac.za/handle/2263/25503

Maxwell, D., Ahiadeke, C., Levin, C., Armar-Klemesu, M., Zakariah, S., \& Lamptey, G. M. (1999). Alternative food-security indicators: Revisiting the frequency and severity of 'coping strategies. Food Policy, 24(4), 411-429.

MRC. (2002). Food Finder 3: Dietary analysis software program, Version 1.0.9, 2002. https://scholar.google.com/scholar?cluster= $1938124684326162227 \& \mathrm{hl}=\mathrm{en} \& \mathrm{as} \_\mathrm{sdt}=2005 \& \mathrm{sciodt}=05$. Accessed 4 December 2019.

National Commission on Hunger. (2015). Freedom from hunger: An achievable goal for the United States of America. UNT Digital Library. Book. https://digital.library.unt.edu/ark:/67531/ metadc799756/. Accessed 4 December 2019.

Ngidi, M. S., \& Hendriks, S. L. (2014). Coping with food insecurity in rural South Africa: The case of Jozini, KwaZulu-Natal. Mediterranean Journal of Social Sciences, 5(25), 278.

Old age pension | South African Government. (n.d.). https://www.gov.za/ services/social-benefits-retirement-and-old-age/old-age-pension? gclid=Cj0KCQjwudb3BRC9ARIsAEa-vUu0HeIt0GyZdakHIxB 2FI5NNdZI8pUO7NzHtbYONqquoZtxPVaVZy4aAkrTEALw wcB. Accessed 4 July 2020.

Oldewage-Theron, W. H., \& Kruger, R. (2008). Food variety and dietary diversity as indicators of the dietary adequacy and health status of an elderly population in Sharpeville, South Africa. Journal of Nutrition for the Elderly, 27(1-2), 101-133.

Oldewage-Theron, W. H., Dicks, E. G., \& Napier, C. E. (2006). Poverty, household food insecurity and nutrition: Coping strategies in an informal settlement in the Vaal triangle, South Africa. Public Health, 120(9), 795-804. 
Oldewage-Theron, W. H., Zotor, F. B., \& Salami, L. (2008, September 1). Health status of an elderly population in Sharpeville, South Africa. Text. https://www.ingentaconnect.com/content/sabinet/ health/2008/00000013/00000003/art00002. Accessed 4 December 2019.

Park, J. Y., Ville, A. S., Schwinghamer, T., \& Melgar-Quiñonez, H. (2019). Heterogeneous factors predict food insecurity among the elderly in developed countries: Insights from a multi-national analysis of 48 countries. Food Security, 11(3), 541-552.

Pillay, N. K., \& Maharaj, P. (2013). Population ageing in Africa. In P. Maharaj (Ed.), Aging and health in Africa (pp. 11-51). Boston: Springer. https://doi.org/10.1007/978-1-4419-8357-2_2.

Shariff, Z. M., \& Khor, G. L. (2008). Household food insecurity and coping strategies in a poor rural community in Malaysia. Nutrition Research and Practice, 2(1), 26-34.

Shetty, P. (2009). Incorporating nutritional considerations when addressing food insecurity. Food Security, 1(4), 431-440.

Shisana, O., Labadarios, D., Rehle, T., Simbayi, L., Zuma, K., Dhansay, A., et al. (2015). The South African National Health and nutrition examination survey, 2012: SANHANES-1: The health and nutritional status of the nation. HSRC Press. http://hdl.handle.net/20.500. 11910/2864. Accessed 1 Dec 2020.

South African Government. (n.d.). Old age pension | South African Government. https://www.gov.za/services/social-benefitsretirement-and-old-age/old-age-pension. Accessed 4 July 2020.

Statistics South Africa, S. (2018). Mid-year population estimates, 2018.

Statistics South Africa, S. (2019). Towards measuring the extent of food security in South Africa. http://www.statssa.gov.za/publications/0300-14/03-00-142017.pdf. Accessed 1 Dec 2020.

The Obesity Society. (n.d.). The Obesity Society - research. Education. Action. The Obesity Society. https://www.obesity.org/. Accessed 4 July 2020.

The World Bank. (n.d.). The World Bank's strategy in South Africa reflects the country's development priorities and its unique leadership position at sub-regional and continental levels. World Bank. Text/HTML. https://www.worldbank.org/en/country/southafrica/ overview. Accessed 4 July 2020.

Thompson, F. E., \& Subar, A. F. (2017). Dietary assessment methodology. In: Nutrition in the Prevention and Treatment of Disease (pp. 5-48). Elsevier. https://doi.org/10.1016/B978-0-12-802928-2. 00001-1.

UNDESA. (2019). Third Review and Appraisal of the Madrid International Plan of Action on Ageing United Nations For Ageing | United Nations For Ageing. https://www.un.org/ development/desa/ageing/news/2017/02/third-review-andappraisal-of-the-mipaa/. Accessed 4 December 2019.

Walsh, C. M., \& van Rooyen, F. C. (2015). Household food security and hunger in rural and urban communities in the Free State Province, South Africa. Ecology of Food and Nutrition, 54(2), 118-137.

WHO. (2019). WHO | ageing and life course. WHO. http://www.who.int/ ageing/en/. Accessed 4 December 2019.

Wight, V., Kaushal, N., Waldfogel, J., \& Garfinkel, I. (2014). Understanding the link between poverty and food insecurity among children: Does the definition of poverty matter? Journal of Children and Poverty, 20(1), 1-20.

Wolmarans, P., Kunneke, E., \& Laubscher, R. (2009). Use of the South African food composition database system (SAFOODS) and its products in assessing dietary intake data: Part II. South African Journal of Clinical Nutrition, 22(2), 59-67.

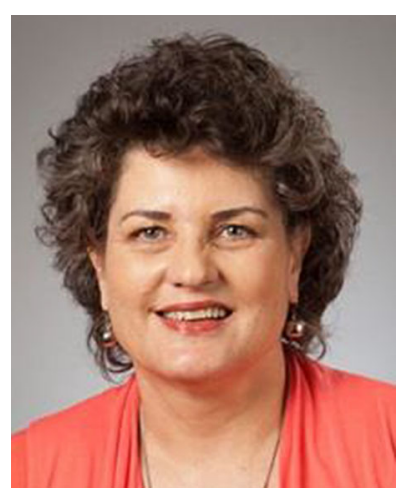

Wilna Oldewage-Theron $(\mathrm{PhD})$ is a Professor of Nutrition at Texas Tech University, USA, where she teaches undergraduate courses in community nutrition and a graduate course in food and nutrition security. She has 20 years Community Nutrition research experience in Africa and is a National Research Foundation (NRF)-rated researcher in South Africa. Her research interests include the factors contributing to household food insecurity and malnutrition in resource-poor communities where she has investigated the effect of various interventions including food fortification, supplementation, nutrition education, food product development and implementation, on dietary diversity and nutritional status of women, children and the elderly.

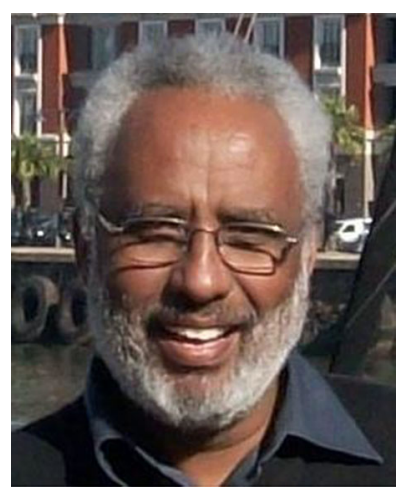

Abdulkadir A. Egal was a tenure tracked professor at the Faculty of Education and Research of the Somali National University from 1981 to 1991 . He authored or coauthored 61 articles, presented 32 papers in international conferences and 12 national conferences, as well as two book chapters and three Soya Nutrition recipe books. Currently a Researcher at Vaal University of Technology (VUT) in South Africa, Prof Egal has successfully supervised 12 MTech students and cosupervised another four MTech and four DTech students. He is currently implementing public health projects in South Africa. He is a reviewer for several journals in human nutrition. 